\title{
Cooking conversion factor of commonly consumed Sri Lankan food items
}

\begin{abstract}
Cooking conversion factor is a factor commonly used in recipe calculation, calculating nutrient content of cooked foods and cost of the cooked foods. Conversion factor is the proportion of weight between cooked edible portion and raw edible portion. It highly depends on cooking methods and type of the food, because there are some changes happened during cooking such as water absorption, water reduction and fat absorption. This study was done to find out the cooking conversion factor of commonly consumed Sri Lankan single food items. Food samples were bought from the local markets, and trimmed off inedible parts from each food samples. Only $100 \mathrm{~g}$ edible portion was taken to processing, like frying, boiling, and tempering. Final weight was taken using digital scale and the conversion factor was calculated. Conversion factor of cereals and cereal products was between 2.2 to 3.5 , for legumes 2 to 2.5 , vegetables was 0.6 to 0.9 and animal foods was mostly below 0.6 , because they mainly contain inedible parts highly than edible parts.
\end{abstract}

Keywords: conversion factor, cooking, boiling, weight change
Volume 6 Issue 4 - 2018

\author{
Adikari AMNT,Thamilini J \\ Department of Applied Nutrition, Faculty of Livestock, Fisheries \\ and Nutrition, Sri Lanka
}

\begin{abstract}
Correspondence: Adikari AMNT, Department of Applied Nutrition, Faculty of Livestock, Fisheries and Nutrition, Wayamba University of Sri Lanka, Makandura, Gonawila (60I70), Sri Lanka, Email thakshila.adikari@yahoo.com
\end{abstract}

Received: July 29, 2018 | Published: August 02, 2018

\section{Introduction}

Food is the amount of the commodity that is available for human consumption during the reference period. ${ }^{1}$ There are several types of food processing methods, such as boiling, steaming, frying, microwave cooking, tempering, baking and etc. these cooking methods may lead to changes in nutrient content and weight of the food. To assess and improve the nutritional status of the population, data about the energy and nutrient content of composite foods are necessary because a large proportion of the food consumed is cooked or prepared by various cooking processing.

Most nutrient databases provide information mainly on the nutrient composition of raw foods. In Sri Lanka, commonly used nutrition composition table also contains nutrient content of raw edible foods. There are no data related to cooked food and their nutrient content. So conversion factor is important to find out the nutrient content of cooked food to improve the nutritional status of the population.

Conversion factor is what is retained in weight of food or dish after preparation, processing or other treatment in relation to the absolute weight of the food before preparation. This may include changes in water or fat content. ${ }^{2}$ Commonly used term for conversion factor is yield factor. These are mostly determined by experimentally. It highly depends on cooking methods and type of food, because there are some changes happened during cooking such as water absorption, water reduction and fat absorption. Conversion factors are mainly considered for the single food items, because these are important to find out the nutrient composition of mixed dishes at ingredient level (Figure 1).

To spend money effectively for purchasing foods, conversion factor is important to find out the amounts to be purchased. As Sri Lanka is a developing country, still it has problems due to malnutrition; this is mainly due to two reasons, one is they don't have enough food to eat and don't have enough money to buy foods. So it is important to find out the correct amounts of foods to be purchased with regards to consumed amount, because a considerable proportion of the purchased food is wasted, spoiled or given to pets (Figure 2).

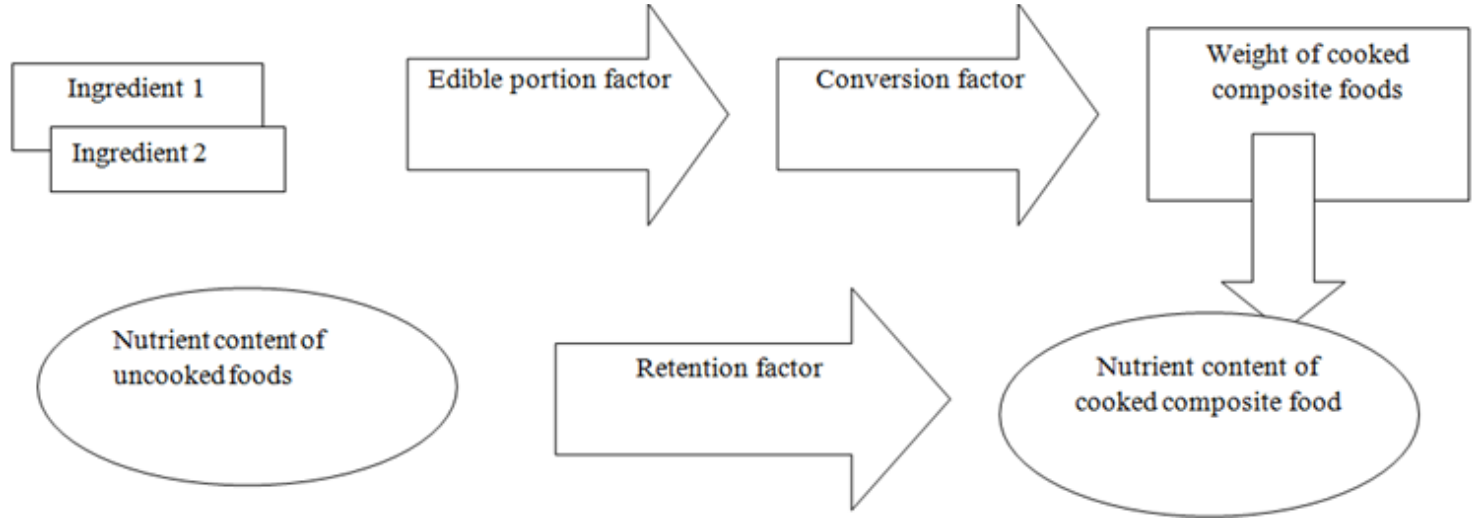

Figure I Overview of calculating nutrient content of cooked foods. 

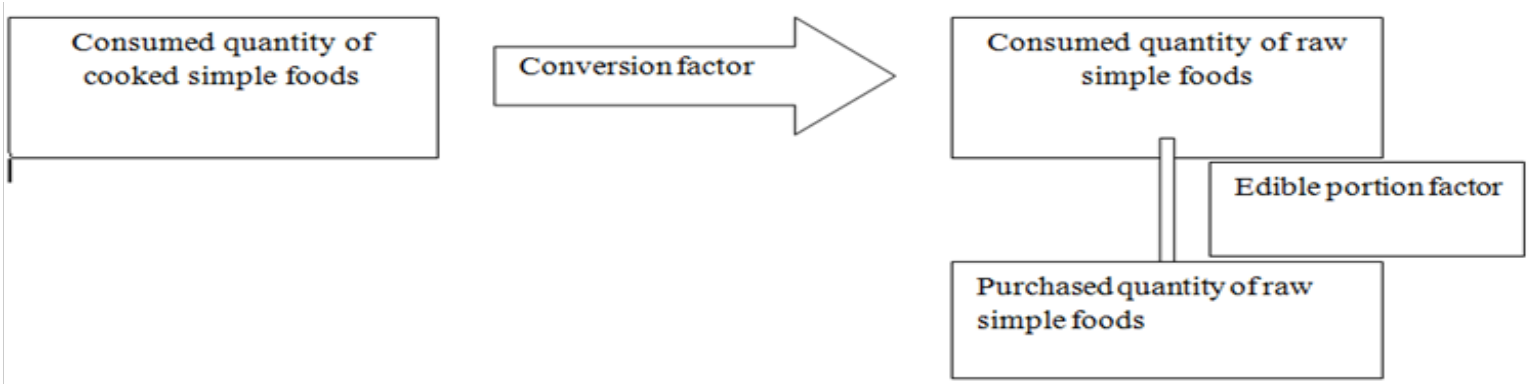

Figure 2 Relationship of conversion factor with purchased quantity and nutrient content of the food.

\section{Materials}

i. $100 \mathrm{~g}$ edible portion of food items (cereals, legumes, vegetables and animal foods)

ii. Digital scale

iii. Cooking vessels

iv. Gas cooker

\section{Methods}

\section{Sample collection}

Commonly consumed Food items in different food groups (Cereals, legumes, vegetables and animal based foods) were purchased from local markets. Cereals are rice (samba, sudu kekkulu (white rice), red rice, paasmathy), noodles (prima, Maggie), as legumes, mung bean, cowpea, green gram, dhal, kadala paruppu and Soya meat, as vegetables both green leafy and fruit vegetables, yams and animal foods chicken, fishes, egg, crabs, dried fish and prawn.

\section{Sample preparation}

Samples were cleaned and the in edible portion was removed. Then only edible portion of the food item was obtained. Finally $100 \mathrm{~g}$ of raw edible portion was taken to processing except egg, because whole egg was taken and the weight of whole egg was measured.

\section{Processing of raw edible portion}

$100 \mathrm{~g}$ raw edible portion were processed by using various cooking methods. Frying, boiling and tempering were performed to food items. Cereals, Cereal products, legumes and some animal foods only processed by boiling. Green leafy vegetables were cooked by using both boiling and frying methods; animal foods were prepared by using boiling and frying methods. For tempering $10 \mathrm{~g}$ oil was used.

\section{Measurement of final weight}

Final weight of each food items were measured by using digital scale. Each value was recorded in a note book to calculate the conversion factor. Measurements were taken three times.

\section{Data analysis}

Conversion factor of each food items were calculated by using following equation and for each food items there were different conversion factors obtained according to the processing methods.

\section{Conversion factor $=\frac{\text { Weight of cooked food }}{\text { Weight of raw edible portion }}$}

Mean value and confident level was calculated by using statistical analysis.

\section{Results}

(Tables 1-4)

Table I Conversion factor of cereals and cereal products

\begin{tabular}{lllllll}
\hline \multirow{2}{*}{ Food items } & \multicolumn{7}{l}{ Processing types } \\
\cline { 2 - 6 } & \multicolumn{7}{l}{ Boiling } & \multicolumn{7}{l}{ Frying } & Tempering \\
\cline { 2 - 6 } & $\mathbf{X}$ & \pm & $\mathbf{X}$ & \pm & $\mathbf{X}$ & \pm \\
\hline Samba rice & 2.82 & 0.01 & - & - & - & - \\
Red kekulu & 3.03 & 0.01 & - & - & - & - \\
Sudu kekulu & 3.10 & 0.01 & - & - & - & - \\
Red rice & 3.52 & 0.03 & - & - & - & - \\
Basmati & 2.87 & 0.01 & - & - & - & - \\
Naadu & 2.79 & 0.02 & - & - & - & - \\
Geeni samba & 3.31 & 0.02 & - & - & - & - \\
Maggie noodles & 2.66 & 0.02 & - & - & - & - \\
Prima noodles & 2.57 & 0.01 & - & - & - & - \\
\hline
\end{tabular}

$X$, mean value of data; -, data not available; \pm , confidence interval.

Table 2 Conversion factors for legumes

\begin{tabular}{lllllll}
\hline \multirow{7}{*}{ Food items } & \multicolumn{7}{l}{ Processing types } \\
\cline { 2 - 7 } & \multicolumn{7}{l}{ Boiling } & \multicolumn{1}{l}{ Frying } & Tempering \\
\cline { 2 - 7 } & $\mathbf{X}$ & \pm & $\mathbf{X}$ & \pm & $\mathbf{X}$ & \pm \\
\hline Cow pea & 2.23 & 0.01 & - & - & - & - \\
Dhal (red) & 2.20 & 0.01 & - & - & - & - \\
Dhal (yellow) & 2.17 & 0.02 & - & - & - & - \\
Kadala pauppu & 2.00 & 0.01 & - & - & - & - \\
Green gram & 2.20 & 0.02 & - & - & - & - \\
Soya meat & 2.43 & 0.02 & - & - & - & - \\
\hline
\end{tabular}

$X$, mean value of data; -, data not available; \pm , confidence interval. 
Table 3 Conversion factors for vegetables

\begin{tabular}{lllllll}
\hline \multirow{2}{*}{ Food items } & \multicolumn{9}{l}{ Processing types } \\
\cline { 2 - 8 } & \multicolumn{2}{l}{ Boiling } & \multicolumn{3}{l}{ Frying } & \multicolumn{3}{l}{ Tempering } \\
\cline { 2 - 8 } & $\mathbf{X}$ & \pm & $\mathbf{X}$ & $\mathbf{\pm}$ & $\mathbf{X}$ & $\mathbf{\pm}$ \\
\hline Beet root & 0.97 & 0.01 & - & - & 0.52 & 0.03 \\
Carrot & 0.94 & 0.06 & - & - & - & - \\
Brinjal & 0.86 & 0.01 & 0.44 & 0.01 & 0.63 & 0.02 \\
Ladies finger & 0.84 & 0.01 & 0.47 & 0.02 & 0.52 & 0.01 \\
Egg plant & 0.83 & 0.02 & 0.43 & 0.01 & 0.58 & 0.01 \\
Potato-with peel & 0.98 & 0.01 & - & - & - & - \\
Potato-without peel & 1.00 & 0.01 & 0.54 & & 0.82 & 0.01 \\
Pumpkin & 0.91 & 0.03 & - & - & - & - \\
Spinach & 0.96 & - & - & - & 0.78 & 0.01 \\
Cabbage & 0.98 & - & - & - & - & - \\
Mukunnuwena & 0.97 & - & - & - & 0.76 & - \\
Beans & 2.50 & - & - & - & - & - \\
Mushrooms & 1.75 & - & - & - & - & - \\
Snake gourd & 0.83 & - & - & - & - & - \\
Manioc & 0.81 & - & 0.41 & 0.02 & - & - \\
Green peas & 0.89 & 0.01 & - & - & - & - \\
Bread fruits & 0.86 & - & - & - & - & - \\
Root vegetables & 0.85 & 0.05 & - & - & - & - \\
Leafy vegetables & 0.95 & 0.03 & - & - & - & - \\
\hline & & & & & & \\
\hline
\end{tabular}

$X$, mean value of data; -, data not available; \pm , confidence interval.

Table 4 Conversion factors for animal foods

\begin{tabular}{lllllll}
\hline \multirow{2}{*}{ Food items } & \multicolumn{9}{l}{ Processing types } \\
\cline { 2 - 7 } & \multicolumn{1}{l}{ Boiling } & \multicolumn{7}{l}{ Frying } & \multicolumn{2}{l}{ Tempering } \\
\cline { 2 - 7 } & $\mathbf{X}$ & \pm & $\mathbf{X}$ & $\mathbf{\pm}$ & $\mathbf{X}$ & \pm \\
\hline Egg-with shell & $\mathrm{I} .01$ & 0.01 & - & - & - & - \\
without shell & 0.91 & 0.03 & - & - & - & - \\
Beef & $0.61-$ & - & - & - & - & - \\
Meat ball & 0.87 & 0.02 & - & - & - & - \\
Crab-with shell & 0.96 & 0.04 & - & - & - & - \\
Without shell & 0.25 & 0.02 & - & - & - & - \\
Shrimp-with shell & 0.95 & 0.02 & 0.38 & 0.02 & - & - \\
Without shell & 0.48 & 0.02 & - & - & - & - \\
Chicken-with skin & 0.40 & 0.03 & - & - & - & - \\
Without skin & 0.36 & 0.01 & - & - & - & - \\
Chicken-with & 0.73 & 0.01 & 0.67 & 0.01 & - & - \\
bone & 0.36 & 0.01 & - & - & - & - \\
Without bone & - & - & 0.80 & 0.02 & - & - \\
Sausage & - & & & &
\end{tabular}

\begin{tabular}{|c|c|c|c|c|c|c|}
\hline Sprat & - & - & 0.72 & 0.02 & - & - \\
\hline $\begin{array}{l}\text { Salaya fish-with } \\
\text { spine }\end{array}$ & 0.84 & 0.01 & 0.63 & 0.01 & - & - \\
\hline Without spine & 0.74 & 0.02 & - & - & - & - \\
\hline Thilapia-with spine & 0.86 & 0.02 & 0.64 & 0.02 & - & - \\
\hline Without spine & 0.72 & 0.01 & - & - & - & - \\
\hline Hurulla-with spine & 0.83 & 0.02 & - & - & - & - \\
\hline Without spine & - & - & - & - & - & - \\
\hline Tuna-with spine & 0.80 & - & - & - & - & - \\
\hline Without spine & 0.63 & 0.01 & - & - & - & - \\
\hline Carp-with spine & 0.88 & 0.03 & - & - & - & - \\
\hline Without spine & 0.62 & 0.03 & - & - & - & - \\
\hline
\end{tabular}

$X$, mean value of data; -, data not available; \pm , confidence interval.

\section{Discussion}

Change in weight during cooking of greater importance when the nutritive value of edible portions of food is to be calculated. Conversion factor of each food items vary with various cooking methods. Conversion factors of cereals and legumes when boiling was more than one and a food like vegetables and animals was less than one. Changes in conversion factor may be due to retention, reduction and absorption of water or fat in food: $:^{3-5}$

i. Increase of the water content

$$
\text { Eg: Boiling of rice }
$$

ii. Reduction of the water content Eg: frying of meat

iii. Fat uptake and reduction of the water content Eg: deep frying of potato

Dry food such as rice, noodles and legumes need certain amount of water to obtain the common ready to eat condition. Additional water is needed to compensate the evaporation loss during cooking, because of that the conversion factor is changed into more than one, as for rice varieties conversion factors varied between 2.5 to 3.2 and for legumes conversion factor are 2.1 to 2.8 . So during cooking of legumes and cereals weight increase happened. ${ }^{6,7}$

When consider vegetables during boiling, water evaporation happened from the food items so weight reduction happened, because of that the conversion factor is less than one, bur some yam varieties like potato is equal to one when boiling, green leafy vegetables is more or less same to one $(\approx 0.90)$. Loss of weight in vegetables mostly due to the collapse of lignocelluloses walls and the extrusion juices contained within them and to shrinkage or to diffusion from dead cells. During boiling cellulose is liberated, parts of the structural material split off the whole and vegetable loss weight. With leafy vegetables weight changes more or less similar to one during cooking, are undoubtedly due to water enclosed between lamellae, e.g. leeks and spinach.

Weight reduction in animal foods is high during cooking, due to that the conversion factor of animal food is 0.50 to 0.90 . When consider animal foods like crabs, shrimps like crustaceans, they contain shells, so that when consider only edible parts the conversion factor is below 0.50 . because of animal foods contain some inedible parts like, bone, 
shells and spine need to consider two conversion factors, one with inedible parts and one without inedible parts, because when boiling cannot boil egg, muscles of crabs and shrimps without shell.

When heat is applied to animal foods, which contain high fat, like raw meat during cooking, weight is lost because fat melts and shrinkage occurs, producing a slow contraction in volume which results in the rupture of cell walls and exudation of water soluble constituents. Water loss is highly due to evaporation. The greater the surface area of a piece of food items of given weight, the greater the rate of loss during cooking. Due to that conversion factor of fatty foods like meat is 0.60 .

\section{Acknowledgements}

None.

\section{Conflicts of interest}

The author declares that there in none of the conflicts.

\section{References}

1. Naska AP, Eckman H, Remaut AM, et al. Methodology for rendering house hold budget and individual nutrition surveys. Public Health Nutr. 2001;4(5B):1153-1158.

2. Heli R, Kati L. Harmonization of recipe calculation procedures. USA: National Public Health institute (KTL); 2007.

3. Bogner A. Tables on weight yield and nutrient retention factors for the calculation of nutrient composition of cooked foods (dishes). Germany: Federal Research Centre for Nutrition; 2002. p. 1-98.

4. Bogner A, Piekaski J. Guidelines for Recipe information and calculation of Nutrient Composition of Prepared foods (dishes). Food Composition and Analysis. 2000;13(4):391-410.

5. Becker W, Helsing E. Food and health Data: their use in nutrition policy making. WHO regional office for Europe; 1991.

6. Lisa C Smith. Measuring food security using household expenditure surveys. International food policy research institute; 2007. 147p.

7. Marie A Mc Carthy. Retention and Yield factors. Human Nutrition Information service; 1980. 